\title{
Creation of a cardiotropic adeno-associated virus: the story of viral directed evolution
}

Lin Yang ${ }^{1 *}$ and Xiao Xiao ${ }^{2 *}$

\begin{abstract}
Adeno-associated virus (AAV) is an important vector system for human gene therapy. Although use of AAV serotypes can result in efficient myocardial gene transfer, improvements in the transduction efficiency and specificity are still required. As a method for artificial modification and selection of gene function, directed evolution has been used for diverse applications in genetic engineering of enzymes and proteins. Since 2000, pioneering work has been performed on directed evolution of viral vectors. We further attempted to evolve the AAV using DNA shuffling and in vivo biopanning in a mouse model. An AAVM41 mutant was characterized, which was found to have improved transduction efficiency and specificity in myocardium, an attribute unknown for any natural AAV serotypes. This review focuses on the development of AAV vector for cardiac gene transfer, the history of directed evolution of viral vectors, and our creation of a cardiotropic AAV, which might have implications for the future design and application of viral vectors.
\end{abstract}

Keywords: Adeno-associated virus, Cardiac gene transfer, Directed evolution, Transduction

\section{Introduction}

The adeno-associated virus (AAV) is one of the smallest viruses, with a non-enveloped capsid measuring approximately $22 \mathrm{~nm}$. It has a linear single-stranded DNA genome of $4.7 \mathrm{~kb}$ in size, which is composed of three gene elements: rep, which encodes the replication proteins; cap, which encodes the capsid proteins; and ITR, which serves as the replication origin and packaging signal (Figure 1). The cap gene is transcribed from a single $\mathrm{p} 40$ promoter, but produces three virion proteins VP1, VP2, and VP3, which differ in length from each other because of the different location of their initiation codons. These three proteins have molecular masses of 87,72 , and $62 \mathrm{kDa}$, respectively, and they assemble in a molar ratio of 1:1:10 to form a near-spherical protein shell of 60 subunits. Despite the fact that an alternative product of the cap gene, associated with the assembly of the AAV particle has been characterized [1], only the three capsid proteins mentioned above are mainly responsible for the tissue tropism and neutralization properties of AAV.

\footnotetext{
* Correspondence: yang|@wh.iov.cn; xxiao@email.unc.edu

'Wuhan Institute of Virology, Chinese Academy of Sciences, 44 Xiaohongshan, Wuhan 430071, Hubei, China

${ }^{2}$ Division of Molecular Pharmaceutics, UNC Eshelman School of Pharmacy, 2070 Genetic Medicine Building CB\#7362, Chapel Hill, NC 27599, USA
}

Despite its prevalence rate of approximately $80 \%$ in human populations, AAV has not been linked to any human illness, and has thus been used as a vector to carry DNA into cells. AAV transduces cells via a multi-step consecutive course $[2,3]$. The virus initially binds to the receptor/co-receptor on surface of the cell, and penetrates into it via receptor-mediated endocytosis. The virion is transported through the endosomal compartment, and most likely escapes into the nucleus through the nuclear pore complex via an as yet unknown mechanism. After nuclear translocation, the capsid uncoats, releasing single-stranded DNA, which is converted into double-stranded DNA for transgene expression. The majority of the AAV vector genomes exist as episomes in the transduced cells [4], which ensures the stable expression of the transgene in post-mitotic tissues (e.g., neuron and muscle) with a lower risk of carcinogenesis. Furthermore, the AAV vector itself elicits only a relatively weak innate and acquired immune response in the hosts [5], which affirms the tolerated transgene expression and the higher safety profile in gene therapy. These two biologic features mean that AAV has great potential as a vector for human gene therapy.

The safety and efficacy of AAV-mediated gene therapy were first verified in clinical trials investigating nervous diseases. Sub-retinal delivery of AAV carrying the gene for 


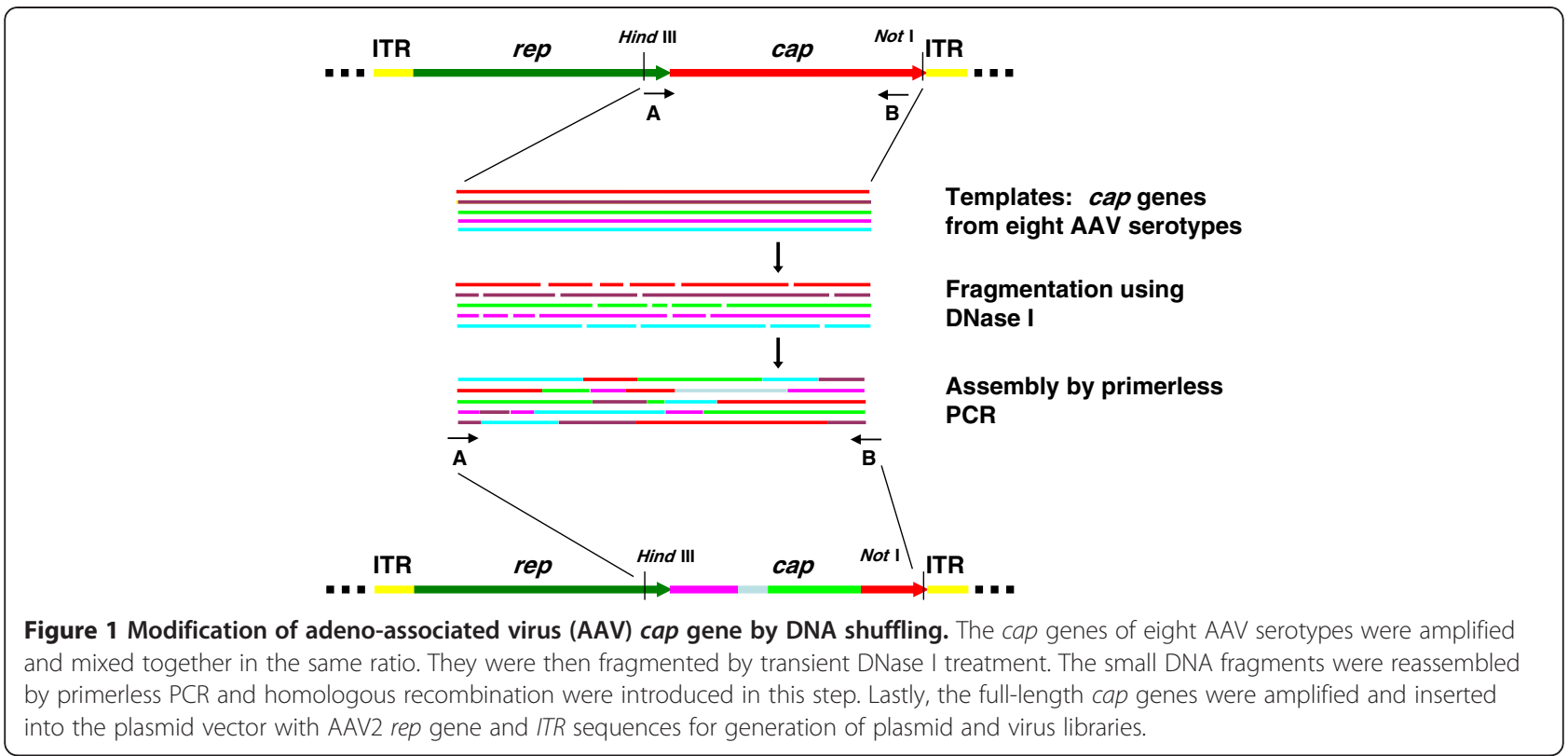

the retinal pigment epithelium-specific $65 \mathrm{kDa}$ protein (RPE65) was verified by several studies to be safe and effectively improve retinal function in patients with Leber's congenital amaurosis [6-8]. Gene transfer of glutamic acid decarboxylase via AAV into the subthalamic nucleus of subjects with Parkinson's disease was well tolerated, and significantly improved the clinical scores of the subjects [9]. More recent clinical trials have expanded the application of the AAV vector to gene therapy of muscular diseases. Calcium upregulation was achieved by intracoronary administration of an AAV1/sarcoplasmic reticulum $\mathrm{Ca}^{2+}$-ATPase vector; the study demonstrated safety and suggested a benefit in the patients of advanced heart failure [10]. Long-term, sustainable alpha-sarcoglycan expression of was detected in the muscles of patients with limb-girdle muscular dystrophy following AAV1-mediated gene transfer regulated by the muscle-specific tMCK promoter [11] (more detailed documentation of current progress in clinical trials using AAV vectors can be found in the review by Mingozzi and High [12]).

Despite the numerous advantages of AAV for gene transfer, several flaws remain to be addressed to improve the versatility of this viral vector. In this review, we provide an introduction to the development of AAV vector for myocardial gene transfer, and focus on how a cardiotropic AAV was created using the directed evolution strategy. The related progress of directed evolution is reviewed to provide a background to this discovery.

\section{Why is a cardiotropic AAV needed? The evolution of AAV} vector biology

For historic reasons, the serotype 2 (AAV2) was the first AAV used as a gene-therapy vector and for detailed biological studies [13]. The AAV2 genome was shown to exist in transduced mouse skeletal muscle as concatamers, and the transgene expression persisted for 1.5 years without induction of humoral or cellular immune responses $[14,15]$. Immediately following this research, AAV2 began to be used for transduction of myocardium in animals. In contrast to the transient transgene expression from adenovirus transduction, up to $50 \%$ of mouse cardiomyocytes were found to be positively transduced 4-8 weeks after intramyocardial injection or coronary artery perfusion with AAV2 [16]. Further studies applied the AAV2 vector to therapeutic gene transfer for the treatment of various heart diseases such as myocardial infarction $[17,18]$, dilated cardiomyopathy [19], and dystrophic cardiomyopathy [20]. Generally, these gene-therapy trials yielded favorable results, with stable and efficient transgene expression achieved in the animal myocardium.

In addition to AAV2, a number of AAV serotypes have been successively identified and their attributes characterized for cardiac gene transfer [21]. Of the known serotypes, AAV1 and AAV6 appeared to transduce the rodent myocardium most promptly and efficiently by direct intramyocardial injection [22,23]. Accordingly, AAV6 has been used for delivery of betaARKct, a peptide capable of inhibiting activation of $\mathrm{G}$ protein-coupled receptor kinase 2 into rats with heart failure, resulting in a significant improvement of cardiac contractility and reversal of left ventricular remodeling [24]. AAV6 was also first successfully employed to achieve widespread transduction of cardiac and skeletal muscles in adult mice by intravenous administration supplemented with vascular permeability factor [25]. A further technical advancement occurred with the use of AAV8, which appeared to be 
more capable than AAV6 of crossing the blood-vessel barrier than AAV6, and efficiently transduced heart and skeletal muscles in mice and hamsters without assistance of vascular permeability factor [26,27]. More recently, AAV9 was shown to have an even higher transduction efficiency in mouse myocardium following intravenous injection [28], and a similar result was observed in non-human primates [29]. Notably, the myocardial transduction efficiency of these AAV serotypes were further validated in different heart disease models via systemic delivery [27,30-32]. These studies built a foundation for further application of AAV vectors to translational medicine.

Such studies on various AAV serotypes have greatly improved the performance of the AAV vector in myocardial gene transfer. However, all of the known AAV serotypes tend to transduce the liver preferentially when administered in vivo, especially with systemic infusion. This feature is a barrier to safe and efficient cardiac gene transfer in human beings, as transduction of unintended organs might result in unnecessary toxicity and immune response. Fortunately, researchers have begun to address this issue, using a variety of approaches. Müller et al. modified the AAV2 capsid by introduction of R484E and R585E mutations to the heparin sulfate proteoglycan binding sites, which improved the specificity of cardiac transduction by AAV vector to some extent [33]. Asokan et al. generated a chimera AAV2i8 by replacing the hexapeptide sequence in the heparan sulfate receptor footprint of AAV2 with that of AAV8 [34]. AAV2i8 selectively transduced cardiac and whole-body skeletal muscle tissues with high efficiency, and showed markedly reduced hepatic tropism. However, it still appears challenging to improve the cardiac transduction of AAV vector as well as to detarget it from liver and other unintended organs. We hypothesized that the directed evolution approach might be an option to achieve this aim because of its highly diverse and flexible applications. The related hypothesis and techniques are documented below.

\section{How can a cardiotropic AAV be created? Hypothesis and techniques for directed evolution of AAV}

AAV is a parvovirus that exhibits some unusual evolutionary features. In a series of investigations on evolution of non-human primate AAV, the AAV cap genes were found to exhibit unexpectedly high levels of gene diversity $[35,36]$. Furthermore, this sequence diversity was caused in part by homologous recombination of coinfecting parental viruses that modified the serologic reactivity and tropism of the virus. These studies not only shed light on the evolutionary mechanism for genetic variation in the AAV genome, but also served as the hypothesis for our research on directed evolution of AAV, i.e., that modification of the AAV cap genes by homologous recombination could plausibly generate AAV variants with novel tissue tropism. These references also indicated that polymerase chain reaction (PCR) might be a more sensitive molecular technique for retrieval of trace AAV variants from animal tissues in comparison to the classic virus isolation methods based on cell culture.

At the time we began our work, some pioneering studies had been carried out into directed evolution of a retrovirus. Genetic recombination between six murine leukemia viruses was achieved by DNA shuffling, and the resulting virus library was selected using the nonpermissive CHOK1 cell line to evolve a completely new tropism [37]. Directed evolution is a method of artificially modifying and selecting genes with desirable properties not found in nature. With respect to DNA shuffling, it was a method originally invented by Stemmer to induce in vitro recombination between homologous genes by PCR (Figure 1) [38]. Sequence variants from a gene or orthologous genes are treated with DNase I to generate random DNA fragments. Using PCR amplification with the homologous DNA as templates and primers reciprocally, these fragments are reassembled into genes of the same size as the original, but with variable functions. Homologous recombination between the DNA fragments occurs, and the reassembled genes are eventually cloned for selection on a biological platform for the specific functions required. Although directed evolution had been used previously to engineer proteins or enzymes, the work of Soong and his colleagues on retrovirus was the first attempt to evolve a gene within the framework of a virus, which expanded the biological application of this technique in biomedicine [37].

One classic method to modify the tropism of a viral vector was to insert a ligand on the virus surface to target the specific cell type. Initially, the targeting ligand was isolated via an indirect approach such as peptide phage display, and then inserted into the virus surface for further characterization. Müller et al. were the first to attempt direct display of a random peptide library on the AAV surface to select the endothelial-cell-targeting ligands [39]. The peptide library was inserted after the R588 site of the AAV capsid, in order to minimize steric change and assure effective ligand exposition. The authors ensured encoding of each displayed peptide by the packaged DNA by using a two-step system for virus library production. After screening on primary human endothelial cells, the selected AAV with targeting peptides exhibited enhanced transduction of coronary endothelial cells but reduced infection of non-endothelial cells. Although this work did not fall into the classic category of directed evolution, it enriched the concept and practice for diversification and screening of virus library.

The first AAV study using directed evolution in the stricter sense was published by Maheshri et al. in 2006 [40]. In that work, the AAV2 cap gene was subjected to 


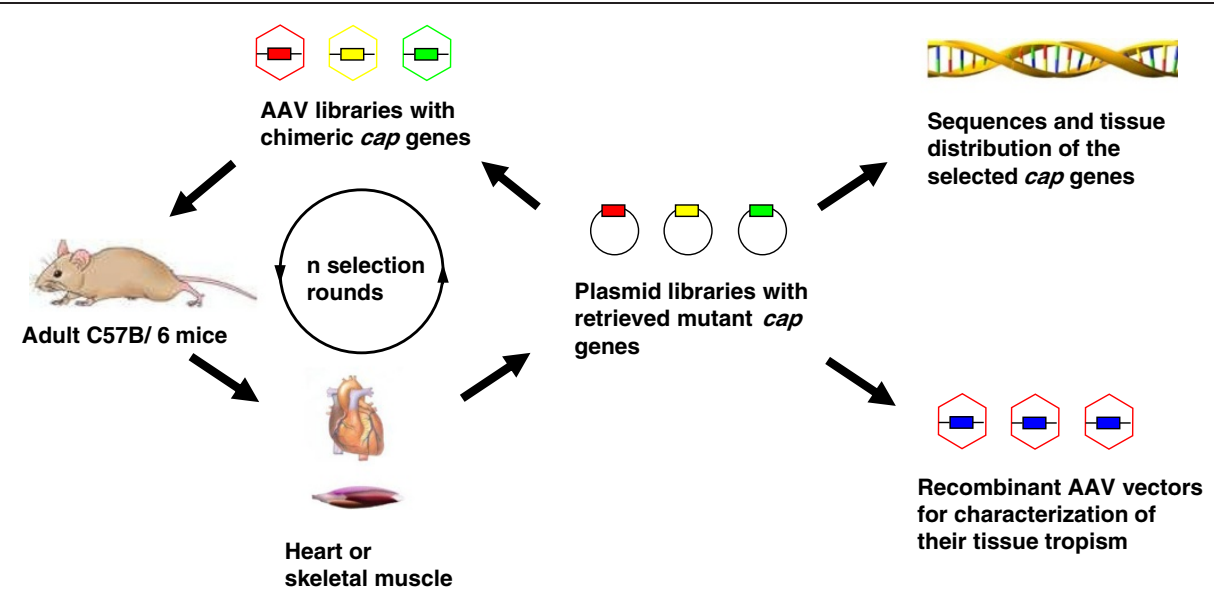

Figure 2 In vivo selection of adeno-associated virus (AAV) variants targeting special tissues. The AAV library with diversified cap genes was injected into adult C57BL/6J mice via the tail vein. Genomic DNA was isolated from the target organs, i.e., the heart or skeletal muscle, and used for PCR amplification of AAV cap genes. The selected cap gene mutants were re-cloned into plasmid vector with AAV rep gene and ITR sequences. The generated plasmid libraries were used for sequence analysis of cap genes and production of AAV libraries for the next screening cycle in mice. After a few rounds of in vivo biopanning, the cap genes enriched in the heart or skeletal muscle but relatively rare in the liver were used for packaging of recombinant AAV vectors for characterization of their tissue tropism.

random mutagenesis, followed by in vitro recombination to construct an AAV library with high capsid diversity. The AAV library was eluted from a heparin-binding column, and AAV mutants with different heparin affinity were separated by fractionation. In accordance with its lower heparin affinity, one AAV mutant showed reduced transduction efficiency when heparan sulfate binding became limiting. In the second application, the AAV library was passaged in 293 cells after pre-incubation with anti-AAV neutralizing serum. After two rounds of modification and selection, one AAV clone, r2.15, was found to display a capacity to resist antibody neutralization that was 96-fold higher than that of wild-type AAV2. The modification methods and selection strategies used in this study would exert an important influence on successive directed evolution research on AAV.

\section{What have we done? The modification and selection of AAV vectors targeting heart and skeletal muscle}

The original aim of our work was to modify the AAV vector for efficient detargeting from liver to muscle. The natural evolution of AAV urged us to use artificial evolution to mimic this course in order to improve the transduction efficiency of AAV in striated muscles. As nine AAV serotypes have now been successively identified, we decided to select eight of these (AAV1-4, AAV6-9) for DNA shuffling of the cap genes, as AAV5 cap genes has been shown to have the largest sequence variation compared with those of other AAV serotypes and might lower the efficiency of in vitro recombination. We also expected that using the natural AAV cap genes as parents for DNA shuffling would ensure a higher viability of the AAV progenies. The shuffled cap genes were cloned into a plasmid backbone with the AAV2 rep gene and ITR sequences (Figure 1). Random clones were picked from the plasmid library for examination of sequence variation and viability of the recombined AAV cap genes. An AAV library was then produced, referring to the two-step method described by Müller et al. [39]. The cap genotype and phenotype of each virus particle were hyphothetically one-to-one correspondent, which would facilitate the successive screening AAV library.

We used two models, one in vitro and the other in vivo, for selection of AAV variants targeting muscles. The in vitro model was composed of a microvascular endothelial cell barrier and a differentiated myocyte culture. The in vivo model was the C57BL/6J mouse, which as an inbreeding strain has been universally used for biomedical research. We hypothesized that the in vivo model would be more realistic, as it should perfectly mimic the physiological environment for the successive gene therapy application of the AAV vector. We first tested the in vivo model by using intravenous injection of an AAV library into mice, followed by isolation of the AAV variants from tissues using PCR (Figure 2). We were able to retrieve the AAV cap genes from several mouse tissues, including heart, skeletal muscle and liver, for genetic analysis and reconstruction of the virus libraries. Therefore, the C57BL/6J mouse model was appropriate for our purpose to screen AAV variants that could bypass the vascular barrier and infect muscles. When the virus library was injected intravascularly into the mice, we were able to intentionally select those AAV variants preferentially infecting a specific organ, such as the heart.

Our aim was to select AAV variants targeting the heart and skeletal muscle. Accordingly, following the first 


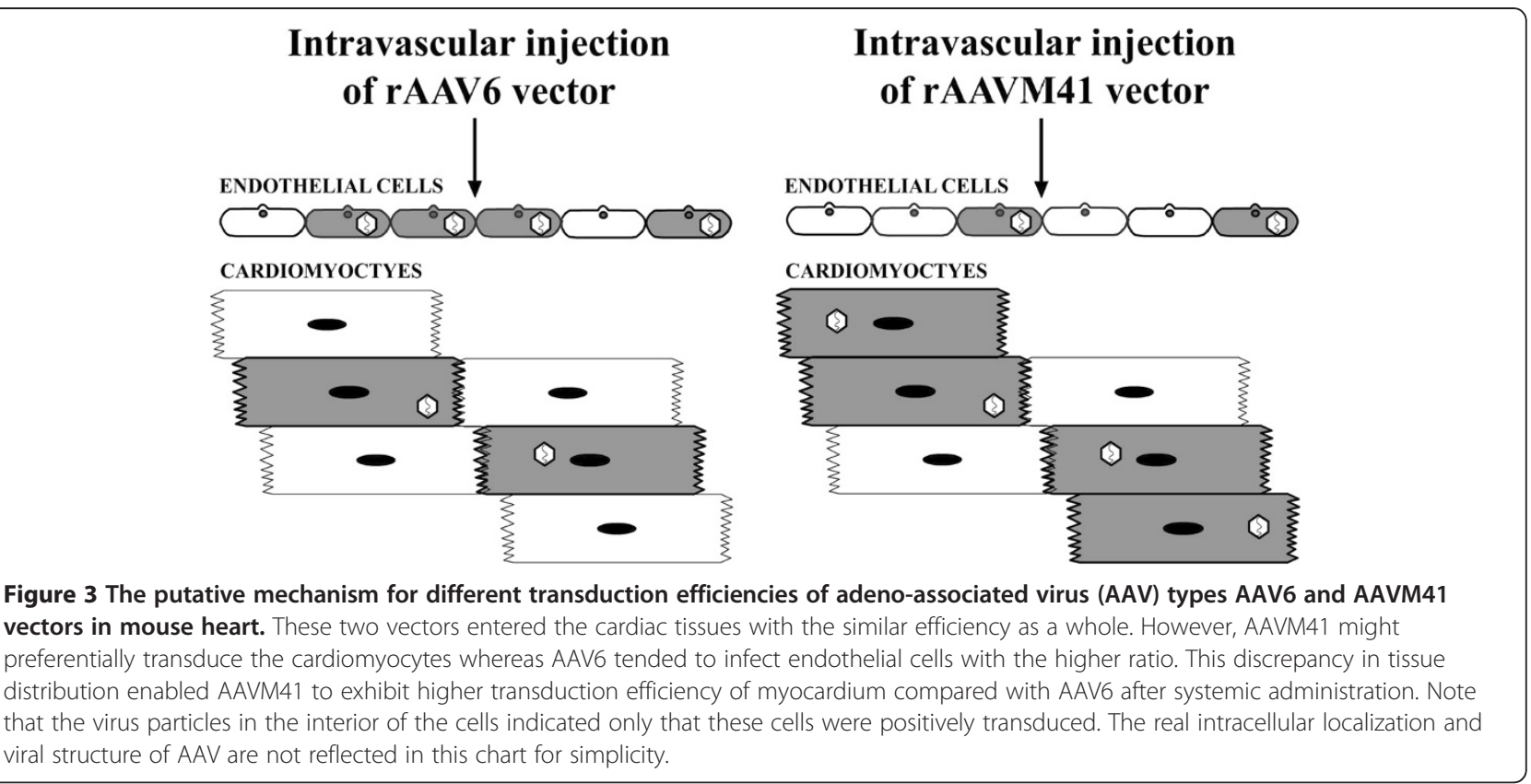

screening, the AAV cap genes were retrieved from both heart and skeletal muscle for reconstruction of the virus libraries for the second screening in mice. The AAV cap genes from the heart and skeletal muscle, respectively, were then sequenced, and their gene frequencies were compared with those from the liver. The AAV mutants enriched in heart or skeletal muscle were selected for further genetic analysis and tropism characterization. Strikingly, we obtained a cardiotropic AAVM41 variant from the mouse skeletal muscle [41]. This was not completely unexpected, as cardiac and skeletal muscles share a similar anatomical origin, and are both subordinate to striated muscles. Our variant, AAVM41, exhibited preferential tropism to mouse myocardium after systemic administration, with a transduction level similar to that of AAV9. However, gene transfer in non-muscle tissues, mainly the liver, was dramatically reduced. This higher affinity to heart rather than liver appeared to be a unique feature of AAVM41, and has not been reported for any naturally evolved AAV variant. Furthermore, the therapeutic potential of AAVM41 was demonstrated by delivery of the $\delta$-sarcoglycan gene into the dystrophic TO2 hamster for efficient amelioration of cardiomyopathy.

It remains unclear as to how the AAVM41 vector evolved its improved efficiency and specificity in myocardial transduction. The sequence of the AAVM41 capsid is closest to that of AAV1 and AAV6 [41]. It also had the similar vector genome copies in the whole heart to that of AAV6 after systemic vector administration. However, the myocardial transduction efficiency of AAVM41 was at least 10 times higher than that of AAV6. By contrast, AAV6 was superior to AAVM41 in direct transduction of primary cardiomyocytes in vitro. One plausible interpretation is that AAV6 tends to infect both endothelial cells and cardiomyocytes in the in vivo physiological environment, whereas AAVM41 could bypass the endothelial cells and preferentially infect the cardiomyocytes when infused into blood stream (Figure 3). Because it is the cardiomyocytes rather than the vascular endothelial cells that occupy the major volume of the heart, this would then account for the fact that AAVM41 generally exhibited a higher transgene expression level in the myocardium. It would be possible to test this hypothesis by comparative study of the vector genome distribution of these two AAV vectors in different cardiac cell types after systemic administration. The recently developed quantitative 3-D tracing microscopic technique will also be helpful to elucidate the mechanism behind the improved cardiac transduction of the AAVM41 vector [42].

\section{Progress and prospects for directed evolution of AAV}

Since the first report of directed evolution of AAV published in 2006, a number of papers have been published in this area. Researchers have designed various strategies for modification of AAV to achieve diverse purposes. Generally, the following development strategies were used.

1. Combinatory application of multiple methods for diversification of the AAV cap gene. The original attempts to modify the AAV cap gene respectively involved random peptide insertion [39], random mutagenesis [40], and DNA shuffling [41]. In some recent work on directed evolution, AAV libraries 
with cap genes diversified by these methods were simultaneously screened in a suitable cell model. As a result, the ShH19 mutant from combinatory libraries produced by DNA shuffling and random mutagenesis was shown to have the highest transduction efficiency in rat astrocytes in vivo [43]. An AAV r3.45 variant with both a peptide insertion and a point mutation was found to have the most efficient transduction of neural stem cells [44]. These results demonstrated the power of simultaneous utilization of multiple gene diversification methods for efficient direct evolution.

2. Realistic biological model for screening of AAV library. In cases where a virus library with high gene diversity has been constructed, the biological platform is likely to be the determining factor for successful directed evolution. An organotypic human airway model was used to screen a virus library produced by the diversification of AAV2 and AAV5 cap genes, and it was found that the AAV2.5 T mutant yielded was able to mediate gene transfer more than 100-fold better than parental strains, and corrected the cystic fibrosis epithelial $\mathrm{Cl}^{-}$transport defect [45]. Furthermore, mouse models were used to evolve AAV targeting tumors or internal organs from random peptide display libraries $[46,47]$. The animal models demonstrated efficacy in improving either the transduction efficiency or specificity of AAV variants, but not both, in these in vivo studies. A realistic biological model closely mimicking the environment for gene therapy application would fulfill the purpose for vector modification more successfully.

3. Combination of directed evolution and rational design. Usually directed evolution and rational design were implemented in parallel for modification of viral vectors. However, in one recent piece of research, bioinformatics analysis was used to select a few loops from the AAV capsid for subsequent semi-random sequence mutagenesis [43]. The resulting AAV random loop library was then used for selection of AAV variants targeting human astrocytes. A second research group first introduced random mutagenesis into the GH loop spanning amino acids 390-627 of the AAV9 capsid [48]. Based on structural analysis, variants with deleterious mutations were triaged for further work, and only AAV clones with potentially beneficial mutations were characterized for vectors detargeting away from the liver. These two reports respectively employed bioinformatic clues for construction of the AAV library and structural analysis for directed selection of AAV variants, which may have important implications for directed evolution work in the future.

\section{Conclusions}

Over the past few years, AAV has risen to prominence as a viral vector system in human clinical trials, especially for the treatment of neurological and muscular diseases. Furthermore, AAV is also an ideal model for directed evolution studies because of its relatively simple genomic structure and the available viral engineering and production methods. However, there is still scope for further development and optimization of directed evolution strategies in modifying this vector. In particular, the practice of human gene therapy continuously presents new challenges for AAV and other viral vectors, such as addressing pre-existing immunity in human populations [49]. Driven by these needs, we expect further advancement in directed evolution of viral vectors, which will ultimately benefit the biomedical research and human health.

\section{Competing interests}

The authors declare that they have no competing interests.

\section{Authors' contributions}

LY and XX participated in the writing of the manuscript and LY drew the figures. Both authors read and approved the final manuscript.

\section{Acknowledgements}

This work was supported by the National Natural Science Foundation of China (31170157), the Natural Science Foundation of Hubei Province (2010CDB10302), and the Youth Innovation Promotion Association, CAS (2012-2015) to Dr Lin Yang, and National Institutes of Health grants AR45967 and AR50595 to Dr Xiao Xiao. Dr Shuai Wang provided technical help in the drawing of Figure 3.

Received: 31 October 2012 Accepted: 16 January 2013

Published: 11 February 2013

\section{References}

1. Sonntag F, Schmidt K, Kleinschmidt JA: A viral assembly factor promotes AAV2 capsid formation in the nucleolus. Proc Natl Acad Sci USA 2010, 107:10220-10225

2. Ding W, Zhang L, Yan Z, Engelhardt JF: Intracellular trafficking of adenoassociated viral vectors. Gene Ther 2005, 12:873-880.

3. Nonnenmacher $M$, Weber $T$ : Intracellular transport of recombinant adenoassociated virus vectors. Gene Ther 2012, 19:649-658.

4. Schnepp BC, Clark KR, Klemanski DL, Pacak CA, Johnson PR: Genetic fate of recombinant adeno-associated virus vector genomes in muscle. J Virol 2003, 77:3495-3504.

5. Zhu J, Huang $X$, Yang Y: The TLR9-MyD88 pathway is critical for adaptive immune responses to adeno-associated virus gene therapy vectors in mice. J Clin Invest 2009, 119:2388-2398.

6. Maguire AM, Simonelli F, Pierce EA, Pugh EN Jr, Mingozzi F, Bennicelli J, Banfi S, Marshall KA, Testa F, Surace EM, Rossi S, Lyubarsky A, Arruda VR, Konkle B, Stone E, Sun J, Jacobs J, Dell'Osso L, Hertle R, Ma JX, Redmond TM, Zhu X, Hauck B, Zelenaia O, Shindler KS, Maguire MG, Wright JF, Volpe NJ, McDonnell JW, Auricchio A, High KA, Bennett J: Safety and efficacy of gene transfer for Leber's congenital amaurosis. N Engl J Med 2008, 358:2240-2248.

7. Bainbridge JW, Smith AJ, Barker SS, Robbie S, Henderson R, Balaggan K, Viswanathan A, Holder GE, Stockman A, Tyler N, Petersen-Jones S, Bhattacharya SS, Thrasher AJ, Fitzke FW, Carter BJ, Rubin GS, Moore AT, Ali RR: Effect of gene therapy on visual function in Leber's congenital amaurosis. N Engl J Med 2008, 358:2231-2239.

8. Cideciyan AV, Aleman TS, Boye SL, Schwartz SB, Kaushal S, Roman AJ, Pang JJ, Sumaroka A, Windsor EA, Wilson JM, Flotte TR, Fishman GA, Heon E, Stone EM, Byrne BJ, Jacobson SG, Hauswirth WW: Human gene therapy for 
RPE65 isomerase deficiency activates the retinoid cycle of vision but with slow rod kinetics. Proc Natl Acad Sci USA 2008, 105:15112-15117.

9. Kaplitt MG, Feigin A, Tang C, Fitzsimons HL, Mattis P, Lawlor PA, Bland RJ, Young D, Strybing K, Eidelberg D, During MJ: Safety and tolerability of gene therapy with an adeno-associated virus (AAV) borne GAD gene for Parkinson's disease: an open label, phase I trial. Lancet 2007, 369:2097-2105.

10. Jessup M, Greenberg B, Mancini D, Cappola T, Pauly DF, Jaski B, Yaroshinsky A, Zsebo KM, Dittrich H, Hajjar RJ, Calcium Upregulation by Percutaneous Administration of Gene Therapy in Cardiac Disease (CUPID) Investigators: Calcium upregulation by percutaneous administration of gene therapy in cardiac disease (CUPID): a phase 2 trial of intracoronary gene therapy of sarcoplasmic reticulum $\mathrm{Ca}^{2+}$-ATPase in patients with advanced heart failure. Circulation 2011, 124:304-313.

11. Mendell JR, Rodino-Klapac LR, Rosales XQ, Coley BD, Galloway G, Lewis S, Malik V, Shilling C, Byrne BJ, Conlon T, Campbell KJ, Bremer WG, Taylor LE, Flanigan KM, Gastier-Foster JM, Astbury C, Kota J, Sahenk Z, Walker CM, Clark KR: Sustained alpha-sarcoglycan gene expression after gene transfer in limb-girdle muscular dystrophy, type 2D. Ann Neurol 2010, 68:629-638.

12. Mingozzi $F$, High KA: Therapeutic in vivo gene transfer for genetic disease using AAV: progress and challenges. Nat Rev Genet 2011, 12:341-355.

13. Samulski RJ, Berns Kl, Tan M, Muzyczka N: Cloning of adeno-associated virus into $\mathrm{PBR} 322$ : rescue of intact virus from the recombinant plasmid in human cells. Proc Natl Acad Sci USA 1982, 79:2077-2081.

14. Xiao X, Li J, Samulski RJ: Efficient long-term gene transfer into muscle tissue of immunocompetent mice by adeno-associated virus vector. J Virol 1996, 70:8098-8108.

15. Fisher KJ, Jooss K, Alston J, Yang Y, Haecker SE, High K, Pathak R, Raper SE, Wilson JM: Recombinant adeno-associated virus for muscle directed gene therapy. Nat Med 1997, 3:306-312.

16. Svensson EC, Marshall DJ, Woodard K, Lin H, Jiang F, Chu L, Leiden JM: Efficient and stable transduction of cardiomyocytes after intramyocardial injection or intracoronary perfusion with recombinant adeno-associated virus vectors. Circulation 1999, 99:201-205.

17. Melo LG, Agrawal R, Zhang L, Rezvani M, Mangi AA, Ehsan A, Griese DP, Dell'Acqua G, Mann MJ, Oyama J, Yet SF, Layne MD, Perrella MA, Dzau VJ: Gene therapy strategy for long-term myocardial protection using adenoassociated virus-mediated delivery of heme oxygenase gene. Circulation 2002, 105:602-607.

18. Iwanaga $Y$, Hoshijima M, Gu Y, I watate M, Dieterle T, Ikeda Y, Date MO, Chrast J, Matsuzaki M, Peterson KL, Chien KR, Ross J Jr: Chronic phospholamban inhibition prevents progressive cardiac dysfunction and pathological remodeling after infarction in rats. J Clin Invest 2004, 113:727-736.

19. Hoshijima M, Ikeda $Y$, Iwanaga $Y$, Minamisawa S, Date MO, Gu Y, Iwatate M Li M, Wang L, Wilson JM, Wang Y, Ross J Jr, Chien KR: Chronic suppression of heart-failure progression by a pseudophosphorylated mutant of phospholamban via in vivo cardiac rAAV gene delivery. Nat Med 2002, 8:864-871

20. Yue Y, Li Z, Harper SQ, Davisson RL, Chamberlain JS, Duan D: Microdystrophin gene therapy of cardiomyopathy restores dystrophinglycoprotein complex and improves sarcolemma integrity in the mdx mouse heart. Circulation 2003, 108:1626-1632.

21. Gao G, Vandenberghe $L H$, Wilson JM: New recombinant serotypes of AAV vectors. Curr Gene Ther 2005, 5:285-297.

22. Su H, Huang Y, Takagawa J, Barcena A, Arakawa-Hoyt J, Ye J, Grossman W, Kan YW: AAV serotype-1 mediates early onset of gene expression in mouse hearts and results in better therapeutic effect. Gene Ther 2006, 13:1495-1502

23. Palomeque J, Chemaly ER, Colosi P, Wellman JA, Zhou S, Del Monte F, Hajjar RJ: Efficiency of eight different AAV serotypes in transducing rat myocardium in vivo. Gene Ther 2007, 14:989-997.

24. Rengo G, Lymperopoulos A, Zincarelli C, Donniacuo M, Soltys S, Rabinowitz JE, Koch WJ: Myocardial adeno-associated virus serotype 6-betaARKct gene therapy improves cardiac function and normalizes the neurohormonal axis in chronic heart failure. Circulation 2009, 119:89-98.

25. Gregorevic P, Blankinship MJ, Allen JM, Crawford RW, Meuse L, Miller DG, Russell DW, Chamberlain JS: Systemic delivery of genes to striated muscles using adeno-associated viral vectors. Nat Med 2004, 10:828-834.

26. Wang Z, Zhu T, Qiao C, Zhou L, Wang B, Zhang J, Chen C, Li J, Xiao X: Adeno-associated virus serotype 8 efficiently delivers genes to muscle and heart. Nat Biotechnol 2005, 23:321-328.
27. Zhu T, Zhou L, Mori S, Wang Z, McTiernan CF, Qiao C, Chen C, Wang DW, Li J, Xiao X: Sustained whole-body functional rescue in congestive heart failure and muscular dystrophy hamsters by systemic gene transfer. Circulation 2005, 112:2650-2659.

28. Inagaki K, Fuess S, Storm TA, Gibson GA, Mctiernan CF, Kay MA, Nakai H: Robust systemic transduction with AAV9 vectors in mice: efficient global cardiac gene transfer superior to that of AAV8. Mol Ther 2006, 14:45-53.

29. Pacak CA, Mah CS, Thattaliyath BD, Conlon TJ, Lewis MA, Cloutier DE, Zolotukhin I, Tarantal AF, Byrne BJ: Recombinant adeno-associated virus serotype 9 leads to preferential cardiac transduction in vivo. Circ Res 2006, 99:e3-e9.

30. Townsend D, Blankinship MJ, Allen JM, Gregorevic P, Chamberlain JS, Metzger JM: Systemic administration of micro-dystrophin restores cardiac geometry and prevents dobutamine-induced cardiac pump failure. Mol Ther 2007, 15:1086-1092.

31. Shin JH, Bostick B, Yue Y, Hajjar R, Duan D: SERCA2a gene transfer improves electrocardiographic performance in aged mdx mice. J Transl Med 2011, 9:132.

32. Pleger ST, Shan C, Ksienzyk J, Bekeredjian R, Boekstegers P, Hinkel R, Schinkel S, Leuchs B, Ludwig J, Qiu G, Weber C, Raake P, Koch WJ, Katus HA, Müller OJ, Most P: Cardiac AAV9-S100A1 gene therapy rescues postischemic heart failure in a preclinical large animal model. Sci Trans/ Med 2011, 3:92ra64.

33. Müller OJ, Leuchs B, Pleger ST, Grimm D, Franz WM, Katus HA, Kleinschmidt JA: Improved cardiac gene transfer by transcriptional and transductional targeting of adeno-associated viral vectors. Cardiovasc Res 2006, 70:70-78

34. Asokan A, Conway JC, Phillips JL, Li C, Hegge J, Sinnott R, Yadav S, DiPrimio N, Nam HJ, Agbandje-McKenna M, McPhee S, Wolff J, Samulski RJ: Reengineering a receptor footprint of adeno-associated virus enables selective and systemic gene transfer to muscle. Nat Biotechnol 2010, 28:79-82.

35. Gao GP, Alvira MR, Wang L, Calcedo R, Johnston J, Wilson JM: Novel adenoassociated viruses from rhesus monkeys as vectors for human gene therapy. Proc Natl Acad Sci USA 2002, 99:11854-11859.

36. Gao G, Alvira MR, Somanathan S, Lu Y, Vandenberghe LH, Rux JJ, Calcedo R, Sanmiguel J, Abbas Z, Wilson JM: Adeno-associated viruses undergo substantial evolution in primates during natural infections. Proc Natl Acad Sci USA 2003, 100:6081-6086.

37. Soong NW, Nomura L, Pekrun K, Reed M, Sheppard L, Dawes G, Stemmer WP: Molecular breeding of viruses. Nat Genet 2000, 25:436-439.

38. Stemmer WP: DNA shuffling by random fragmentation and reassembly: in vitro recombination for molecular evolution. Proc Natl Acad Sci USA 1994, 91:10747-10751

39. Müller OJ, Kaul F, Weitzman MD, Pasqualini R, Arap W, Kleinschmidt JA, Trepel M: Random peptide libraries displayed on adeno-associated virus to select for targeted gene therapy vectors. Nat Biotechnol 2003, 21:1040-1046.

40. Maheshri N, Koerber JT, Kaspar BK, Schaffer DV: Directed evolution of adeno-associated virus yields enhanced gene delivery vectors. Nat Biotechnol 2006, 24:198-204.

41. Yang L, Jiang J, Drouin LM, Agbandje-McKenna M, Chen C, Qiao C, Pu D, Hu $X$, Wang DZ, Li J, Xiao X: A myocardium tropic adeno-associated virus (AAV) evolved by DNA shuffling and in vivo selection. Proc Natl Acad Sci USA 2009, 106:3946-3951.

42. Xiao PJ, Li C, Neumann A, Samulski RJ: Quantitative 3D tracing of genedelivery viral vectors in human cells and animal tissues. Mol Ther 2012, 20:317-328

43. Koerber JT, Klimczak R, Jang JH, Dalkara D, Flannery JG, Schaffer DV: Molecular evolution of adeno-associated virus for enhanced glial gene delivery. Mol Ther 2009, 17:2088-2095

44. Jang JH, Koerber JT, Kim JS, Asuri P, Vazin T, Bartel M, Keung A, Kwon I, Park KI, Schaffer DV: An evolved adeno-associated viral variant enhances gene delivery and gene targeting in neural stem cells. Mol Ther 201 1, 19:667-675.

45. Excoffon KJ, Koerber JT, Dickey DD, Murtha M, Keshavjee S, Kaspar BK, Zabner J, Schaffer DV: Directed evolution of adeno-associated virus to an infectious respiratory virus. Proc Natl Acad Sci USA 2009, 106:3865-3870.

46. Michelfelder S, Kohlschütter J, Skorupa A, Pfennings S, Müller O, Kleinschmidt JA, Trepel M: Successful expansion but not complete restriction of tropism of adeno-associated virus by in vivo biopanning of random virus display peptide libraries. PLoS One 2009, 4:e5122.

47. Ying Y, Müller OJ, Goehringer C, Leuchs B, Trepel M, Katus HA, Kleinschmidt JA: Heart-targeted adeno-associated viral vectors selected by in vivo 
biopanning of a random viral display peptide library. Gene Ther 2010, 17:980-990.

48. Pulicherla N, Shen S, Yadav S, Debbink K, Govindasamy L, AgbandjeMcKenna M, Asokan A: Engineering liver-detargeted AAV9 vectors for cardiac and musculoskeletal gene transfer. Mol Ther 2011, 19:1070-1078.

49. Manno CS, Pierce GF, Arruda VR, Glader B, Ragni M, Rasko JJ, Ozelo MC, Hoots K, Blatt P, Konkle B, Dake M, Kaye R, Razavi M, Zajko A, Zehnder J, Rustagi PK, Nakai H, Chew A, Leonard D, Wright JF, Lessard RR, Sommer JM, Tigges M, Sabatino D, Luk A, Jiang H, Mingozzi F, Couto L, Ertl HC, High KA, Kay MA: Successful transduction of liver in hemophilia by AAV-Factor IX and limitations imposed by the host immune response. Nat Med 2006, 12:342-347.

doi:10.1186/1743-422X-10-50

Cite this article as: Yang and Xiao: Creation of a cardiotropic adenoassociated virus: the story of viral directed evolution. Virology Journal 2013 10:50.

\section{Submit your next manuscript to BioMed Central and take full advantage of:}

- Convenient online submission

- Thorough peer review

- No space constraints or color figure charges

- Immediate publication on acceptance

- Inclusion in PubMed, CAS, Scopus and Google Scholar

- Research which is freely available for redistribution 